\title{
Automatic LPG Leakage Detection and Cylinder Booking USING Arduino-UNO
}

\author{
Biradar Smita Satyakumar ${ }^{1}$, Hubale Supriya Bhagwan ${ }^{2}$, Kadam Pooja Govind ${ }^{3}$ \\ BE Student, Electronics and Telecommunication, VPKBIET, Baramati, India ${ }^{1,2,3}$
}

\begin{abstract}
In 21st Century Peoples are busy in their rushing life so they do not have time for their safety and security that's why we are dealing with this issue regarding home security. In kitchen, while using LPG Cylinder there are many problems occurs such as the time required for LPG Cylinder booking it also phases the problem with gas leakage. Our project can help for monitoring and detecting gas leakage by using the sensor as soon as gas leakage is detected an alert message sent to remote location user and it also stuck the gas supply by automatically switching off the regulator and immediately turns on the exhaust fan. It assurer the safety from leakage of the gas accident dysponea and detonation .this system has an additional purpose that is monitoring the weight of LPG cylinder continuously by using weighing sensor by informing user about gas left in the cylinder this system will help to purchaser to know about whether they are cheated by gas distributor providing less amount of LPG. The main advantage is automatically booking an LPG cylinder by sending an SMS to the distributor company and also alert the user with the help of GSM technology. It also helps physically challenged people by making them independent and secure them from any kitchen speculative.
\end{abstract}

Keywords: GSM module, Servo Motor , Load cell, HX711 amplifier, ATmega328p controller,LCD,MQ-5 sensor,Exhaust fan, Regulator.

\section{INTRODUCTION}

LPG (Liquefied Petroleum Gas ) is used for past decades as an industrial fuel, chemical industry, and homelike purpose. LPG consist of commercial propane $(\mathrm{C} 3 \mathrm{H} 8)$ and butane $(\mathrm{C} 4 \mathrm{H} 10)$ with saturated as well as unsaturated hydrocarbons from C2 to C5 In India, due to the short storage of LPG, it is not possible to supply LPG through pipelines.As technology being improved many distributors company and gas agencies implemented interactive voice response system i.e.IVRS. In the present time, everyone is busy in their daily life they do not have time to check how much gas is remaining in a cylinder and find difficult to book the cylinder. in domestic usage or any other application leakage of gas is dangerous to human life .so our main aim to design a safety-oriented system and automatic booking without human intervention. This system consist of MQ-5 sensor for continuously monitoring an leakage of gas present in the air when sensor detected concentration of gas in air reaches the specific level it sends an alert SMS to registered mobile number of a user also automatically switch OFF the regulator with the help of servo motor, activate buzzer for indicating leakage is detected and switch $\mathrm{ON}$ exhaust fan.

This project also provide automatic booking of cylinder by using load cell in which load cell continuously measuring weight of cylinder with the help of HX711 amplifier when the weight of cylinder goes below the predefined level further it will register your cylinder booking through GSM technology by sending SMS to distributor company and also send alert SMS to user.

\section{LITERATURE SURVEY}

Dr. Walter Snelling was first produced LPG which is the mixture of butane, propane and the small number of hydrocarbons because of different nature of LPG it is used for domestic fuel, heating, automobile fuel, industrial fuel etc. Day by day demand of LPG is raising. Before the development of household electronic gas detectors in the 1980s and 90 presence of gas was detected by using chemically infused paper when gas comes in contact with paper then paper changes its color.

Android-based automatic gas detection and indication robot produced by Manohar Raju and N.Sushma Rani in 2008. They developed mini mobile robot which is capable to detect gas leakage in hazardous places when gas leakage is occurred in a specific place the robot immediately read and send the data to android mobile through wireless communication[1].

Gas leakage is a major concern with commercial premises, residential and gas-powered transportation vehicles which is introduced by Mahalingam. One of the preventive measures to avoid the danger related to gas run is to put in a gas run detector at vulnerable locations. the main intention of this work is to present the design of a cost-effective automatic alarming system which can find out leakage of liquefied petroleum gas in various premises. to meet UK occupational 
health and safety standards this proposed system is designed[2].

In the year 2014, Ashish Kushwah, Khyati Asthana, Hitendra Rawat, Akanksha Shivhare, designed a system, they introduced safety issues against thieves, leakage and fire accidents. in this situation, their system sends a message to the emergency number provided to it.'in the proposed system we have designed LPG gas monitoring and automatic cylinder booking with the alert system. these reports focus on the detection of economic fuels like LPG gas, petroleum, alcohol etc.and alert surrounding people about the leakage through a message and also turning ON the buzzer[3].

\section{HARDWARE DESCRIPTION}

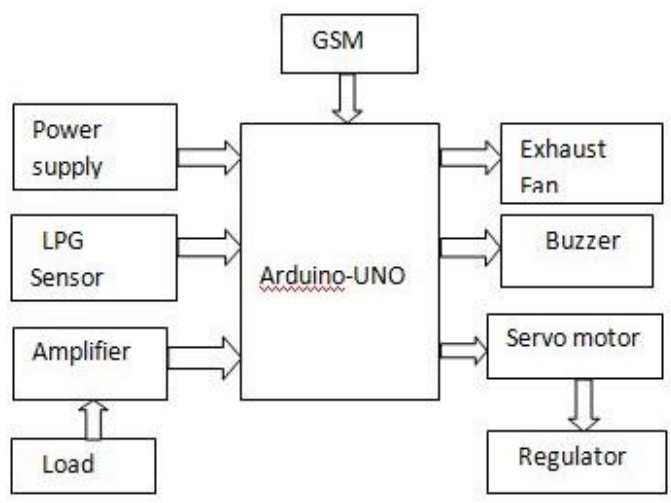

Fig. Block diagram

\section{Arduino UNO:}

Arduino UNO is a microcontroller board base on Atmega328p. Atmega328p board is a powerful development platform-base on the microcontroller. It uses Atmega16U2 faster transfer rates and more memory. It uses Arduino IDE (Integrated Development Environment) software which is used for writing program and upload them.

\section{Features:}
a) Input voltage: 7 to 12 .
b) 6 Analog Inputs.
c) $32 \mathrm{k}$ Flash memory.
d) $16 \mathrm{MHZ}$ Clock speed.
e) 14 Digital I/O Pins.

\section{Load cell(YZC-1B):}

A load cell is one type of transducer which converts pressure into an electrical signal. The different type of load cell that exists includes Hydraulic load cell Pneumatic load cell and Strain gauge load cell. Strain gauge type load cell is commonly used.

\section{Features:}
a) Capacity: 3 to $200 \mathrm{~kg}$
b) Material: Aluminium - alloy or alloy steel.
c) Type: Parallel beam type.

\section{HX-711 Amplifier:}

The HX711 Amplifier is an Analog to Digital Converter.The HX-711 load cell amplifier is used to get measurable data coming out for load cell and strain gauge the HX\&11 Amplifier accepts five wires from the load cell these pins are labelled with colours RED, BLACK, WHITE where yellow is an option ground wire and remaining four wire comes from the strain gauge on the load cell.there may be somewhat variable in colours of wire from the module to module.

\section{GSM Module(900A):}

GSM module is used to establish communication between a controller and a GSM system. It required a SIM Card similar to Mobile phones to activate communication with the network. Similar to Mobile phones for identification they also have an IMEI number.

\section{Features:}
a) Dual-Band $900 / 1800 \mathrm{MHz}$
b) Control via AT commands
c) Operation Temperature: $-40^{0} \mathrm{C}$ to $+85^{0} \mathrm{C}$ 


\section{International Journal of Advanced Research in Computer and Communication Engineering}

Vol. 7, Issue 12, December 2018

\section{MQ-5 Sensor:}

MQ-5 is a semiconductor gas sensor that detects the presence of isobutane, LPG, and Propane gas. the sensor can operate at the temperature range from -10 to $500 \mathrm{C}$ and it consumes less than $150 \mathrm{~mA}$ at $5 \mathrm{~V}$.

\section{Features:}

a) Supply voltage $-5 \mathrm{v}$

b) Small sensitivity to alcohol, smoke

c) Fast response time: $<10 \mathrm{~S}$

d) High sensitivity to LPG

e) Detecting range: 200 to $10000 \mathrm{ppm}$

\section{Servo motor:}

A servo motor is a linear actuator or rotary actuator that allows for precise control of linear or angular position, acceleration and velocity. For position feedback, it consists of a suitable motor coupled to a sensor It also needs a sophisticated controller, frequently dedicated module designed emphatically for use with servo motor

\section{Features:}

a) Operating speed: $0.1 \mathrm{~s} / 60$ degree

b) Operating voltage: $4.8 \mathrm{~V}(5 \mathrm{~V})$

c) Operating temperature: 0 to $550 \mathrm{C}$

d) Working torque: $2 \mathrm{Kg} / \mathrm{Cm}$

e) Structural Material: copper metal teeth, coreless motor, double ball bearing

\section{$7 . \quad$ Buzzer:}

The buzzer is used to indicating that leakage of gas has occurred and also indicate that whole cylinder is empty

\section{Exhaust Fan:}

The exhaust fan is a mechanical fan that hangs above the stove in the kitchen it removes heat smoke combustion gases and steam from the air by evacuation of the air and filtration

\section{Regulator:}

The regulator is a device which has a function of maintaining designated characteristics. It can be used generally to connect any set of various controls or devices for regulating or controlling items or objects.

\section{Power supply:}

The power provides could be a relation to a supply of power.

A system that supplies electrical or other types of energy to an output load or group of a load is called a power supply unit. Here in our system, we need $(12 \mathrm{~V}, 1 \mathrm{~A}) \mathrm{DC}$ power supply for all electronics involved in a project. this requires a step-down transformer, voltage regulator, rectifier and filter circuit for generation of $(12 \mathrm{~V}, 1 \mathrm{~A}) \mathrm{DC}$ power

\section{CONCLUSION}

By implementing this project we can help the people providing safety and security by sensing the leakage of gas and also save their time by providing automatic gas booking. It is very useful for industrial purpose as well as domestic purpose. The programming used for this system is simple and can be easily understood we used $\mathrm{C}$ language. A respite of use of this system makes the project user friendly.

\section{REFERENCES}

[1] A. Mahalingam, R. T. Naayagi, N. E. Mastorakis, “Design and Implementation of an Economic Gas Leakage Detector", (2012).

[2] Ch. Manohar Raju and N. Sushma Rani “An Android Based Automatic Gas Detection and Indication Robot”, International Journal of Computer Engineering and Applications, Vol 8, Issue I, Oct 14.

[3] Hitendra Rawat, Ashish Kushwah, Khyati Asthana, Akanksha Shivhare "LPG Gas Leakage Detection \& Control System" (2014).

[4] R.NareshNaik, P.SivaNagendra Reddy,S.Nanda Kishore, K.Tharun Kumar Reddy, “Arduino Based LPG gas Monitoring \& Automatic Cylinder booking with Alert System", IOSR Journal of Electronics and Communication Engineering (IOSR-JECE), Volume 11, August 2017.

[5] Bhagyashree Prof. Mahesh.R. K, “A Review of Unified Automatic GAS Leakage Detector Using Arduino and GSM Module", (2017).

[6] Ashutosh N. Ganorkar, Semkant R. Pahune, Abhishek K. Damedhar, Jitendra Waghmare, “A Review on: Automatic LPG Cylinder Booking and Leakage Detection using Arduino UNO", Vol. 8 Issue No.3 (2018).

[7] K. R. Chowdhury, M. Di Felice, "Search: a routing protocol for mobile cognitive radio ad hoc networks," Computer Communication Journal, vol. 32, no. 18, pp. 1983-1997, Dec.20

[8] K. M. Passino, "Biomimicry of bacterial foraging for distributed optimization,” IEEE Control Systems Magazine, vol. 22, no. 3, pp. 52-67, 2002. 